\title{
The study of the billboard effectivity of Umbul Siblarak
}

\author{
Phaksi Arwendha ${ }^{1}$,Deny Tri Ardianto ${ }^{2}$ and Nooryan Bahari ${ }^{3}$ \\ \{Phaksiarwendha@gmail.com¹, denytri@staff.uns.ac.id ${ }^{2}$, \& nooryanbahari@staff.uns.ac.id ${ }^{3}$ \} \\ 1,2,3Universitas SebelasMaret, Surakarta, Indonesia
}

\begin{abstract}
In the current digital era, print promotion media such as billboard is still widely used as a means to attract audiences attention to the content of advertising material contained within it. Billboard in many applications is placed in certain locations that are considered strategic and able to attract the attention of road users. This study examines the feasibility of umbulsiblarak billboard and analyzes it that is based on design principles. The techniques for collecting data through observation, documentation, and literature studies. The approach in this study uses outdoor media theory to analyze the design of whole layout umbulsiblarak billboard.
\end{abstract}

Keywords: effectivity, billboards, umbul siblarak.

\section{INTRODUCTION}

Bilboard is an outdoor promotional media that has long been known and utilized by the community. In this digital era, billboard is still considered an effective medium for introducing products to consumers. In this regard, it enriches the quality of living and makes life and communication more pleasant because it creates awareness and educates people about products and services [1]. In addition, outdoor promotional media billboard that has a deeper value attract the attention of the audience. According to[2] billboard has a special advantage in that it is generally seen in settings that there is less competition for people atention. Generally, billboards are placed in the certain prominent of the strategic places such as business centers or protocol roads that many people go through with the aim of making billboards easily visible to the audience. Advertising through billboards with the presentation of attractive designs is very useful in building a positive outlook on brand products in the community. According to Taylor et al [3], Traditional management assumptions that billboard is mainly awareness and interest builders. Therefore, the presentation of material and design layouts found on billboards also plays a crucial role in conveying information to the audience so that messages are easily accepted by the audience.

The phenomenon of using billboards is not only used to promote products in the form of goods or services but also to certain companies. In its billboard application, it is also widely used in tourist attractions as a media that provides information as well as a means to promote all the facilities that exist within the object to the audience.

UmbulSiblarak is one of the bathing attractions in the village of Sidowayah, Polanharjo sub-district, Central Java, which uses billboards as one of its promotional media. Competition in the field of tourism lately is so fierce that every tourist manager seeks to promote his or her tourism products with a variety of promotional media in the form of digital promotional media 
and in the form of printed promotional media such as billboards. The phenomenon of billboard that uses in Siblarak pennant attractions seems to be still in a hurry and inefficiently presenting the material. This is because the arrangement of layouts, the use of colors and fonts on the umbulsiblarak billboards do not refer to the design methods for effectively conveying visual information to the audience. This problem needs to be examined further considering that one of the successes of promotional media to convey messages to audiences lies in the material content and overall design layout of the promotional media. As with the content elements, the design elements can be used to reduce either cognitive or affective responses [4].

\section{METHOD}

This research uses descriptive type by using a qualitative approach.qualitative research involves collecting data in the form of naturalistic verbal report- for example, interview transcripts or written accounts and the analysis conducted on these is textual [5]. Data collected from interviews, field notes, observations, and other documents then to be analyzed based on the data obtained.This study seeks to evaluate systematically, factually and accurately about the facts regarding the effectiveness of the use of billboards as a promotional media of umbul siblarak. The interview data obtained from several visitors who passed the location of umbul siblarak billboard was placed. The interviews data then to be collected and analyzed to obtain the validity of information relating to the application of umbul siblarak billboard. The analysis technique in this study uses triangulation data which includes reducing data to pursing the data needed, presenting data, and drawing conclusions.

\section{RESULT AND DISCUSSION}

Umbul siblarak is a bathing place built by the government of Sidowayah village, Polanharjo sub-district, Klaten district, Central Java as a tourist attraction. The source of the spring used to irrigate the umbul siblarak comes from the umbul kemanten which are located close together. The development process of umbul siblarak has been going on since 2015 on an area of 2.5 hectares. In his marketing, Umbul Siblarak has not used much media promotion, except that around the access to Umbul Siblarak there is a billboard that contains material in the form of information about the facilities inside.

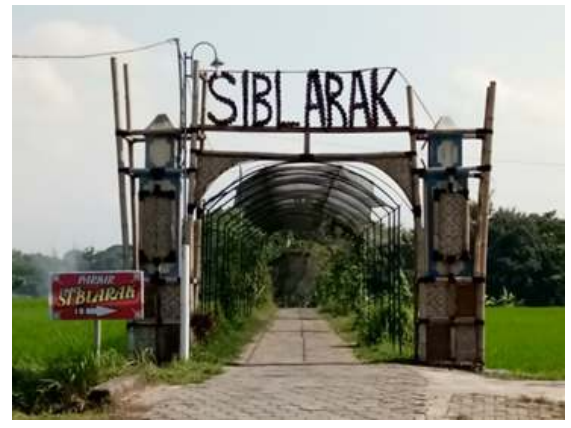

Fig. 1. The Enterance of Umbul Siblarak

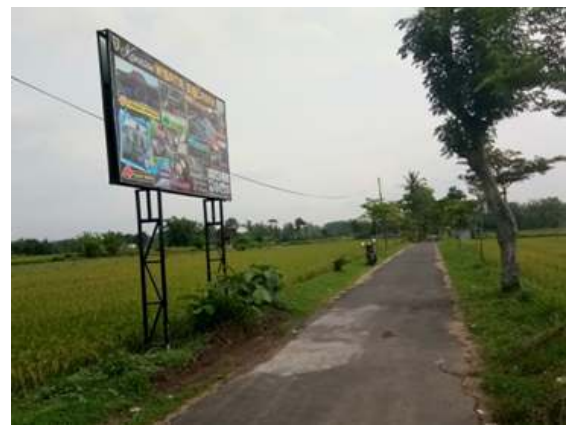

Fig. 2. The Billboard at the enterance of Umbul Siblarak

The laying of the billboard is on a fast track so that many road users ignore the billboard. the opinion of some visitors, the position of laying the umbul siblarak's billboard is difficult to 
get attention to considering its less strategic laying position. In addition, some visitors also find it difficult to pay attention to the contents of the the billboard that looks complicated and difficult to read.

\section{a. The Analysis of Visual Element on UmbulSiblarak's Billboard}

In the previous study on billboards, Henderson [6] made the following theories about effective billboard design. There are key elements of the billboard media, such as:

- $\quad$ Concept: the creative understanding of the plan

- Writing (text composition): minimum content and with high effectiveness

- $\quad$ Plan: form of a poster

- $\quad$ Layout: should be compact and simple visual way

- $\quad$ Graphics: color and size of project

- $\quad$ Selecting a font: easy to be seen and read

- $\quad$ Distance: adjust the layout with sight distance

- $\quad$ Product Identity: focus on product in billboard

- Shape: the shape and design of the billboard

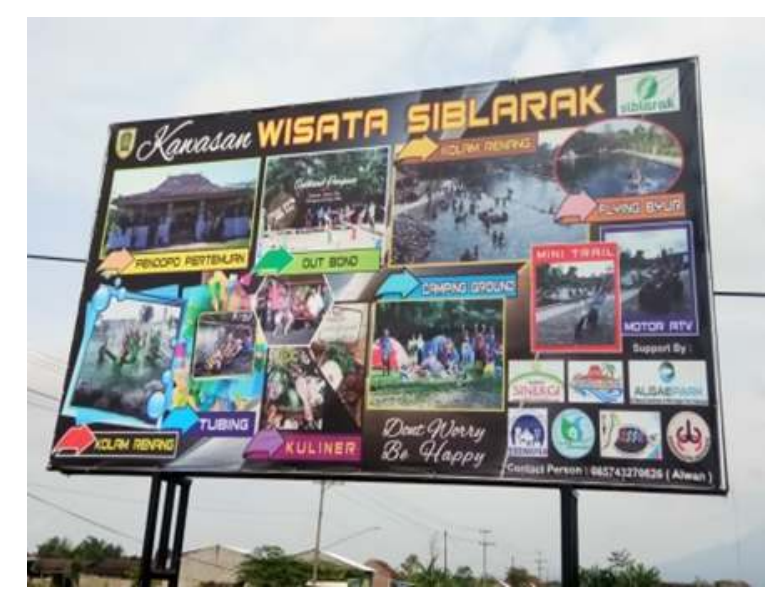

Fig. 3. The display of Umbul Siblarak Front View Billboard design

\subsection{Effective Content}

An advertising media such as billboards will not be separated from the content which is the main part of the design element that contains information from the ad. Interesting content on billboards generally does not contain too much material but is right on target and is supported by typographic elements that meet the requirements. The elements of graphic typo include:

- Clarity or legibility is the quality of letters that make the letter readable. The most important aspect of this concept is that the influence of the viewers can be designed in a manner that is compelling[7]. In an advertising design work, pieces, stacks, etc. can occur which can cause a decrease in clarity in the letters. To avoid this, you must know and understand the characters in the form of a letter properly. So that there will be a clear relationship between letters one to another.In combining letters with other letters both to form a word, sentence, or do not have to pay attention to the 
relationship between letters to one another, especially the distance between letters. The distance between letters cannot be measured, but must be seen and felt. The use of letters that are less precise on billboards can reduce the audience's ease in reading information which results in the messages being delivered not entirely captured. If this happens, it can be said that the ad failed because it was less communicative. The density and estrangement of letters in a design can also affect the balance in the design of the ad.

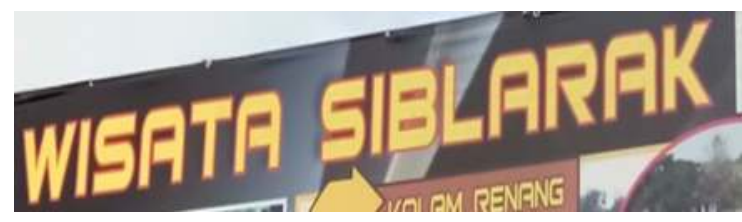

Fig. 4. The application of typografy in the Billboard of Umbul Siblarak

- Distance of vision or visibility is the ability of a letter, word, or sentence in an advertising design to be read in certain reading distances. The letters used for headlines in brochures are certainly different from those used for outdoor media advertising. Outdoor media advertisements must use letters large enough to be read from a certain distance. Each advertising design generally has a reading distance target, and the letters used in typographic design must be legible in that distance. In this case the bulb siblarak billboards have a fairly short reading distance of around 10 meters. This is because the typography size used in the billboard is relatively small when compared to the available layout. So that it appears that the position of the content inside the billboard is quite difficult to read at a certain distance.

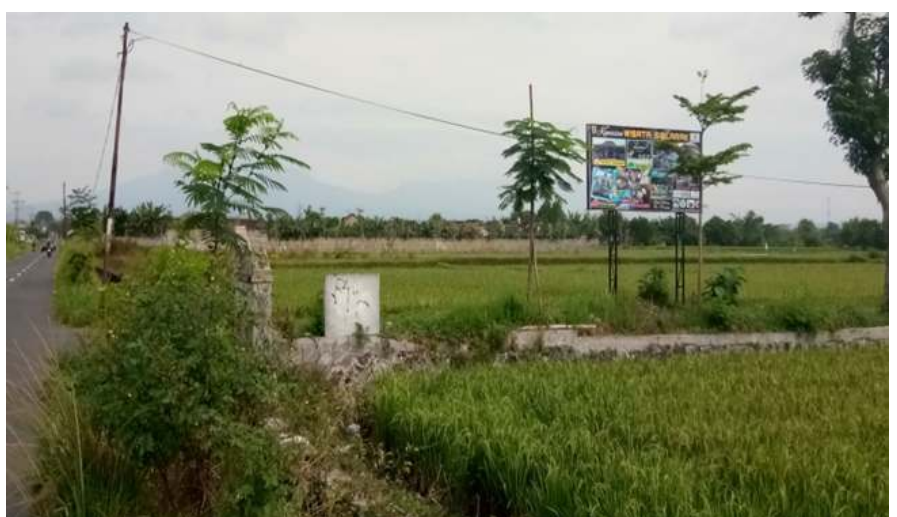

Fig. 5. Billboard size comparison with the viewing distance from the main road

- The interest in reading or clarity, namely the ability of the letters used in an advertisement design can be read and understood by the intended target audience. Therefore, the information conveyed must be able to be understood by the audiences, so that the audiences are interested in reading. Hence, from the four principal types of typography, each of them has a main goal, namely to ensure that information on advertisements delivered through billboards is conveyed properly and correctly. 


\subsection{Illustration}

The illustration used in the umbul siblarak billboards in the form of photography. The object used as an illustration is a photo of a collection of facilities that are placed in the object. However, the display of photos that are so much arranged without considering the layouts makes the illustrations on the billboard can not be seen clearly. The object of photography usually becomes more realistic, exclusive and persuasive. Besides, the illustration in photography has several utilities. The several utilities are to describe a comparison of showing the news and to capture something.

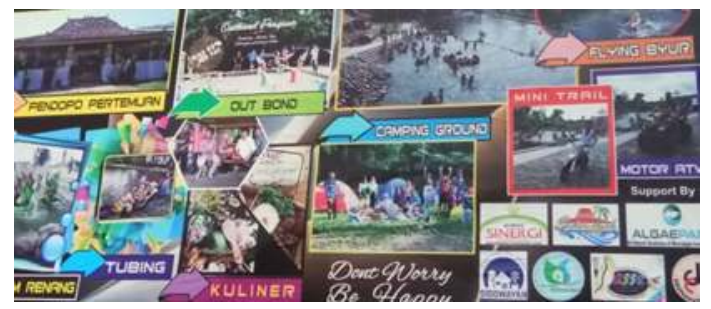

Fig. 6. The model of serving umbul siblarak billboard photo illustrations

\subsection{Colors}

Color is an important element that can influence an advertising design. Color selection and processing or merging with one another can give a distinctive impression and have a unique character because each color has different properties. In design elements, the application of color can influence the audience's psychological condition. Using colors can help the viewer to create a better association with what is advertised, improve readability and emphasize key information or simply generate a better overall visual impact [8]. In this case, the Billboard Siblarak uses a lot of color components, each of color components has characteristics that influence the psychology of the audience. Color is fundamental to sight, identification, interpretation, perceptions, and senses. Some colors evoke psychological reactions such as warmth, relaxation, danger, energy, purity, and death[9].

\subsection{The Layout of Visual Element}

Layout is an amalgamation of all visual elements contained in the advertisement including typography, illustrations, and colors, which are arranged or compiled according to need and as attractive as possible. In this case, the billboards contained in Umbul Siblarak seem to ignore the composition between the laying of content and images so that the level of readability of the content becomes disturbed. Image placement can have a great impact on the visual aesthetic of a layout [10]. Thus, the combination of visual elements needs to be considered so that the advertisement can be seen properly and correctly. Graphic design is not meant for communicating messages to the masses but it is communicating specific message to specific audiences effectively[11].

\section{CONCLUSION}

The success of an advertising media in delivering messages toward audiences needs to be supported by the presentation of attractive designs. By adhering to the design principles of a billboard will be more effective in conveying advertising messages toward the audiences. Billboards at UmbulSiblarak need to pay attention at the presentation of layouts to be more organized between the laying of content and photos so that the messages that are in the advertising can be easily understood by audiences. in addition, the laying of billboards in 
strategic locations also has an important role in the successful to delivery of advertisements message on billboards. By being supported by an attractive layout and strategic placement, a billboard will be an outdoor promotional media that is more effective in conveying messages to the audience

\section{REFERENCE}

[1] O. E. Bankole, "Urban environmental graphics: impact, problems and visual pollution of signs and billboards in Nigerian cities," Int. J. Educ. Res., vol. 1, no. 6, pp. 1-12, 2013.

[2] C. R. Taylor, G. R. Franke, and H.-K. Bang, "Use and effectiveness of billboards: perspectives from selective-perception theory and retail-gravity models," J. Advert., vol. 35, no. 4, pp. 21-34, 2006.

[3] J. L. Fortenberry and P. J. McGoldrick, "Do Billboard Advertisements Drive Customer Retention?: Expanding the 'AIDA' Model to 'AIDAR,"' J. Advert. Res., p. JAR-2019, 2019.

[4] R. Lohtia, N. Donthu, and E. K. Hershberger, "The impact of content and design elements on banner advertising click-through rates," J. Advert. Res., vol. 43, no. 4, pp. 410-418, 2003.

[5] J. A. Smith, Qualitative psychology: A practical guide to research methods. Sage, 2015.

[6] Y. (Islamic A. U. Rajei, M. (Islamic A. U. Ahmadi, mojtaba (Islamic A. U. Rahmani, and mahmoud (Islamic A. U. Samadi, "Impact of Key elements of advertising billboard on consumersand prioritize the elements using the AHP technique," Int. J. Innov. Res. Adv. Eng., vol. 1, no. 10, pp. 334-342, 2014.

[7] D. F. B. Eldesouky, "Visual hierarchy and mind motion in advertising design," J. Arts Humanit., vol. 2, no. 2, pp. 148-162, 2013.

[8] A. Donev, "Typography in Advertising," tomas bata university in zlin, 2015.

[9] S. Kurt and K. K. Osueke, "The effects of color on the moods of college students," SAGE Open, vol. 4, no. 1, p. $2158244014525423,2014$.

[10] H. Thompson, "Trends in Layout Design of Feature Articles in Outdoor Magazines," ELON J., p. 16, 2018.

[11] R. Sharma, "Impact and Relevance of Design Principles in Magazine Covers: A Content Analysis." 